\title{
Mechanical and Microstructural Response of an Aluminum Nanocomposite Reinforced with Carbon-Based Particles
}

\author{
José Manuel Mendoza-Duarte ${ }^{a}$, Ivanovich Estrada-Guel ${ }^{a, b *}$, Francisco Carlos Robles-Hernandez, $^{b}$ \\ Caleb Carreño-Gallardo ${ }^{a}$,Claudia López-Meléndez ${ }^{c}$, Roberto Martínez-Sánchez ${ }^{a}$
}

\author{
${ }^{a}$ Centro de Investigación en Materiales Avanzados - CIMAV, Laboratorio Nacional de Nanotecnologia, \\ Miguel de Cervantes, No. 120, C.P. 31136, Chihuahua, Mexico \\ ${ }^{b}$ Department of Mechanical Engineering Technology, University of Houston, Houston, TX 77204-4020, USA \\ ${ }^{c}$ Universidad La Salle Chihuahua, Pról. Lomas de Majalca, No. 11201, CP 31020, Chihuahua, Mexico
}

Received: October 14, 2015; Revised: June 1, 2016; Accepted: June 25, 2016

The present work deals with the study of some aluminum (Al) composites reinforced with metallized-graphite (MG) particles prepared by mechanical milling and powder metallurgy routes. Density, morphology evolution and mechanical performance of composites were investigated as a function of MG concentration and milling time. The as-milled powders were characterized by X-ray diffraction and optical/electron microscopy; meanwhile, the mechanical testing was carried out on cylindrical specimens prepared from powders by powder metallurgy. Evidence reveals that high-energy ball milling induce a homogeneous dispersion of graphite nanoparticles in the Al matrix; this is related to an enhancement of hardness and strength response of studied composites. The composite sample with $0.5 \%$ MG addition (in weight) reached an increase of $40 \%$ on hardness and $50 \%$ on strength (compared with pure Al sample); nevertheless an adverse effect was observed with longer milling and/or higher MG concentration.

Keywords: composites, high-energy ball milling, powder metallurgy

\section{Introduction}

Efforts have been made to development new aluminum (Al) based materials for aerospace and aeronautical applications. Some of the advantages offered on those new Al-base components include: better wear resistance, strength to rupture ${ }^{1-4}$, modulus $^{5,6}$, thermal stability ${ }^{7}$, among others. The aim of a composite material is to get a spectrum of properties that cannot be obtained by any of the constituent alone.

The engineering to design a composite aims to achieve properties that are superior to those observed in castings or forged products ${ }^{8,9}$. Metal matrix composites (MMC's) are fabricated by different methods such as: powder metallurgy ${ }^{10}$, spray atomization, co-deposition, plasma spraying, stir casting ${ }^{1-4}$ and squeeze casting, where the processing method has a strong influence on the final properties of the composites (e.g. mechanical, tribological, etc. $)^{11,12}$. Composites manufactured by the casting route ${ }^{5,6,8}$ are usually challenging due to the different nature of the reinforcement that may have poor wettability and agglomeration problems ${ }^{13}$. Some reinforcements are highly reactive particularly at high temperature, which induce unwanted reactions between components ${ }^{14}$. As a result this can affect the strength of final composite.

On the other hand, powder metallurgy reduces segregation, porosity, process temperature, grain size ${ }^{6}$, recrystallization rate ${ }^{5}$ and improves homogeneity of final products ${ }^{15}$. The powder metallurgy products can be consolidated by hot extrusion or

* e-mail: ivanovich.estrada@cimav.edu.mx sintering ${ }^{10,11}$. Fiber or particulate graphite is recognized by their high strength and low density ${ }^{16}$. This makes this type of reinforcements attractive in the manufacturing of MMC's, particularly Al-matrix composites, due to its low density, high workability and increased properties ${ }^{17}$.

A major goal of this work is to show that we have been identified a methodology to improve bonding between particles, which in turn, minimize porosity and prevent undesirable chemical reactions ${ }^{8}$ that is accomplished by mechanical milling (MM) resulting an high homogeneity and grain size refining $(100 \mathrm{~nm} \text { or less) })^{18-20}$. Experience has shown that milling of $\mathrm{Al}$ and graphite is not the right processing method ${ }^{21}$. In fact, some authors have used copper, silicon, magnesium and nickel-coated graphite as a ways to improve diffusion and bonding with the Al matrix: In the case of nickel (Ni) addition, it serves as a stronger overcoat of the graphite particles, but $\mathrm{Ni}$ coating reacts with $\mathrm{Al}$ forming brittle NiAl intermetalics at the interface, reducing significantly the toughness of the composites ${ }^{22}$. On the other hand, copper was used to improve surface wettability and interface bonding between $\mathrm{Al}$ and graphite particulate, using a wet cementation process, unfortunately with the following drawbacks: agitating produced an uneven copper-coat on the surface of graphite particulates, great accumulation of particles at the rim of the reaction box due centrifugal force action and unwanted chemical reactions ${ }^{23}$. Here we show an alternative mechanical method to improve the wettability of Al-graphite couple without the above disadvantages. 
The mechanical and microstructural characterization of some Al matrix composites reinforced with copper coated graphite is described. Our method is unique in the sense that we discovered a route to cover copper with graphite giving quite promising results along with the fact that it is cost effective, fast and in solid state.

\section{Material and Methods}

Preparation method is divided into two parts: a) synthesis of the reinforcement copper coated graphite (metallized graphite, MG), and b) Formulation of Al-MG composites. Raw materials are: graphite $(99.9 \%$ purity and $-850+200$ $\mu \mathrm{m}$, in size), copper $(99.5 \%-100 \mu \mathrm{m})$ and aluminum $(99.5 \%$ $-45 \mu \mathrm{m})$ in powder form.

\subsection{MG preparation}

A weighted mixture of graphite and metallic copper with the ideal composition tested before of 15 at. $\% \mathrm{Cu}^{24}$ was processed in a high-energy SPEX $8000 \mathrm{M}$ mill. The milling media was hardened steel vial and balls. The balls to powder ratio was 5 to 1 (in weight). Milling was accomplished after a period of $4 \mathrm{~h}$, under an inert argon atmosphere.

\subsection{Composite preparation}

The Al-MG composites were prepared by milling mixtures of $\mathrm{Al}$ powder and $\mathrm{MG}$ particles with the following concentrations: $0,0.5$ and 1.0 (in weight \%). This second process was carried out in a ZOZ-CM01 Simoloyer device for times between 1 to $8 \mathrm{~h}$. Methanol was added to as a control agent $(0.8$ wt. \%).

\subsection{Characterizations and Testing}

Scanning electron microscopy (SEM) characterization was conducted on a JEOL-JSM 7201F SEM/EDS. X-ray diffraction (XRD) analyses were carried out using a PAN analytical $X^{\prime}$ pert PRO diffractometer using a $\mathrm{CuK} \alpha(\lambda$ $=1.5405 \AA$ ). The density of the sintered specimens was calculated according to Archimedes' method. Coldconsolidated samples were obtained by room temperature pressing $(950 \mathrm{MPa})$ in a cylindrical die followed by sintering at $823 \mathrm{~K}$ for $3 \mathrm{~h}$ under an inert Ar atmosphere. Hardness tests were performed following the ASTM E18 standard using a Wilson Rockwell hardness meter (model C503 R) using HRF scale (1/16" ball indenter and $60 \mathrm{kgf}$ of load) and compression tests were done in an Instron universal machine (model 4468); both test were achieved at room temperature $\left(20^{\circ} \mathrm{C}\right)$. Using the experimental strain stress plot by triplicate, the mechanical behavior of samples was determined as the strength at the elastic limit.

\section{Results and Discussion}

\subsection{Morphological analysis}

The initial particles (Figure 1a) present a spheroidal morphology characteristic of atomized metal powders. The particles milled for $4 \mathrm{~h}$ (Figure $1 \mathrm{~b}$ ) are large due to a particleparticle weld process, forming big agglomerates. With further milling, the fracture of agglomerates (due hardening by cold working) reduces the particle size of the sample (Figure 1c). The Figure 2 shows the internal characteristics of the particles (cross section), finding a typical convoluted lamellar morphology at short milling times (Figs. 2a and 2c), after $8 \mathrm{~h}$ of milling a more homogeneous structure with absence of coarser layers is evident (Figures $2 \mathrm{~b}$ and $2 \mathrm{~d}$ ). As a general result, the composite particles become more homogeneous and isotropic with the milling process. Once the powders are homogeneous in size, further milling can refine the layered structure as Figures $2 \mathrm{~b}$ and $2 \mathrm{~d}$ show. On the other hand, the Al-0.5\%MG composite does not form large particles even after $4 \mathrm{~h}$ of milling (Figure 1e), with $8 \mathrm{~h}$ of milling is noticeable that particles get a flat morphology (Figure 1f). We attribute those changes to a modification of the weld and fracture equilibrium induced by the presence of the MG particles. The small particles (white arrows) are identified as the reinforcement phase composed by copper and carbon (Figure 2c and 2d). MG particles were homogeneously distributed by trapping them between the ductile lamellae and surrounding by the Al matrix during the milling process (further milling means higher homogeneity), as was reported elsewhere ${ }^{16}$. Also, the lamellar microstructure, homogeneity and MG distribution in the Al-1.0\%MG composite was improved after $8 \mathrm{~h}$ of milling. Figure 3 a shows a close-up of a single MG particle, where is possible to observe that this "single" particle is in fact composed by a group of nanometric agglomerates. Through energy dispersive spectroscopy (EDS) elemental analyses we could identify the presence of carbon and copper on the matrix (Figures $3 a$ and $3 b$ ). Figure $3 c$ exhibits a transmission electron microscopy (TEM) micrograph of a particle showing its chemical composition of copper and carbon. Apparently, this thin layer of carbon is enough to maintain the copper particles insoluble during the sintering process; otherwise they would be easily dissolved due to the high solubility of copper in aluminum particularly at high temperature ${ }^{25}$.

\subsection{X-Ray diffraction}

Figure $4 \mathrm{a}$ shows the XRD pattern of the Al-0.5\%MG composites in powder form, processed at different milling times. The presence of the MG particles is not detected by XRD due to their low concentration. The intensity of the Al reflections decreases with milling time, milling of ductile Al particles induces significant microstructural changes such as severe plastic deformation accompanied by strain 

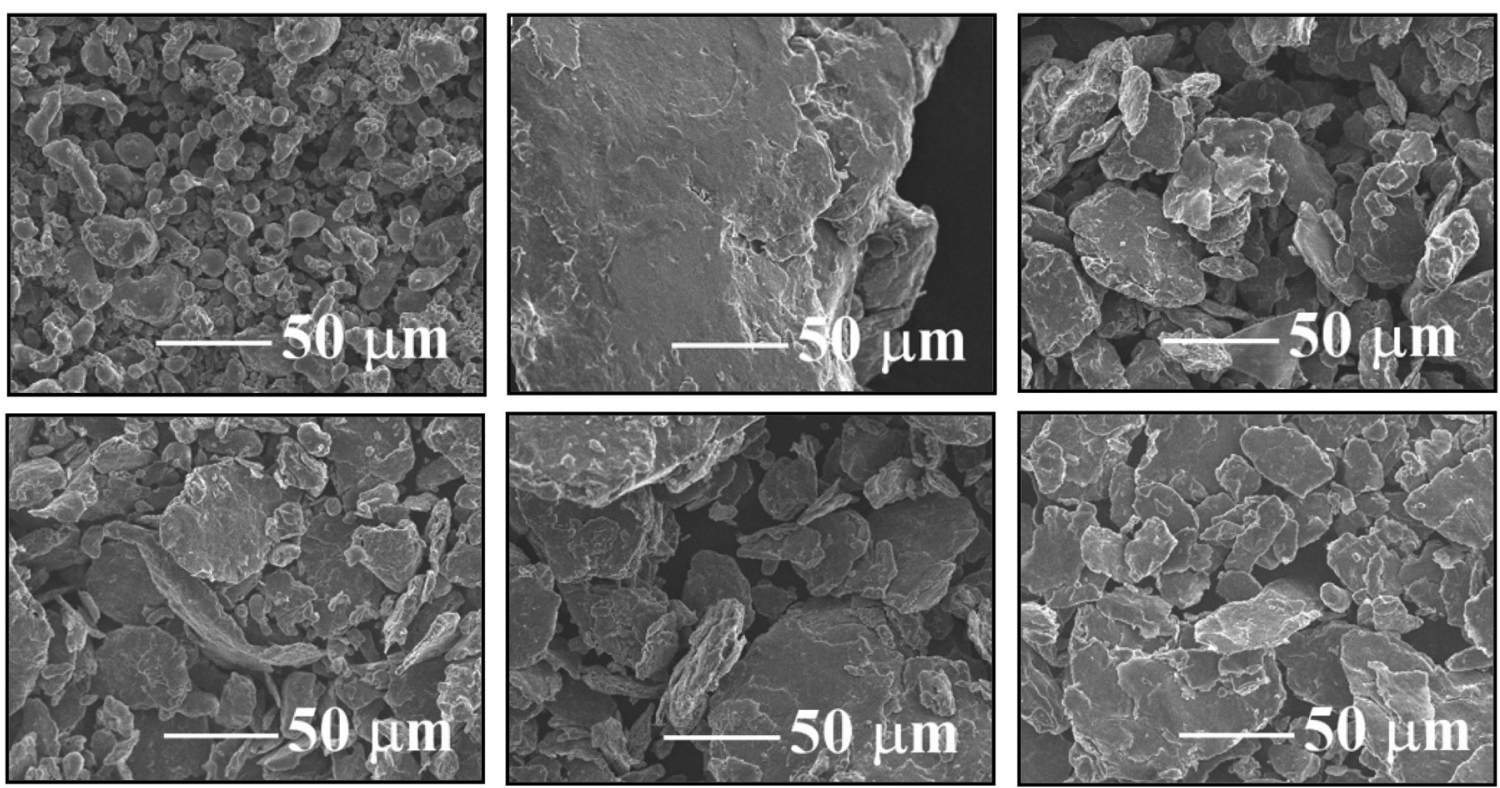

a) $0 \mathrm{~h}$

b) $4 \mathrm{~h}$

c) $8 \mathrm{~h}$

d) $2 \mathrm{~h}$

e) $4 \mathrm{~h}$

f) $8 \mathrm{~h}$

Figure 1. SEM-SE micrographs of sample powders: $\mathrm{Al}$ and $\mathrm{Al}-0.5 \% \mathrm{MG}$ composite at different milling times: a) $0 \mathrm{~h}, \mathrm{~b}-\mathrm{e}) 4 \mathrm{~h}, \mathrm{c}-\mathrm{f}) 8 \mathrm{~h}$ and d) $2 \mathrm{~h}$.
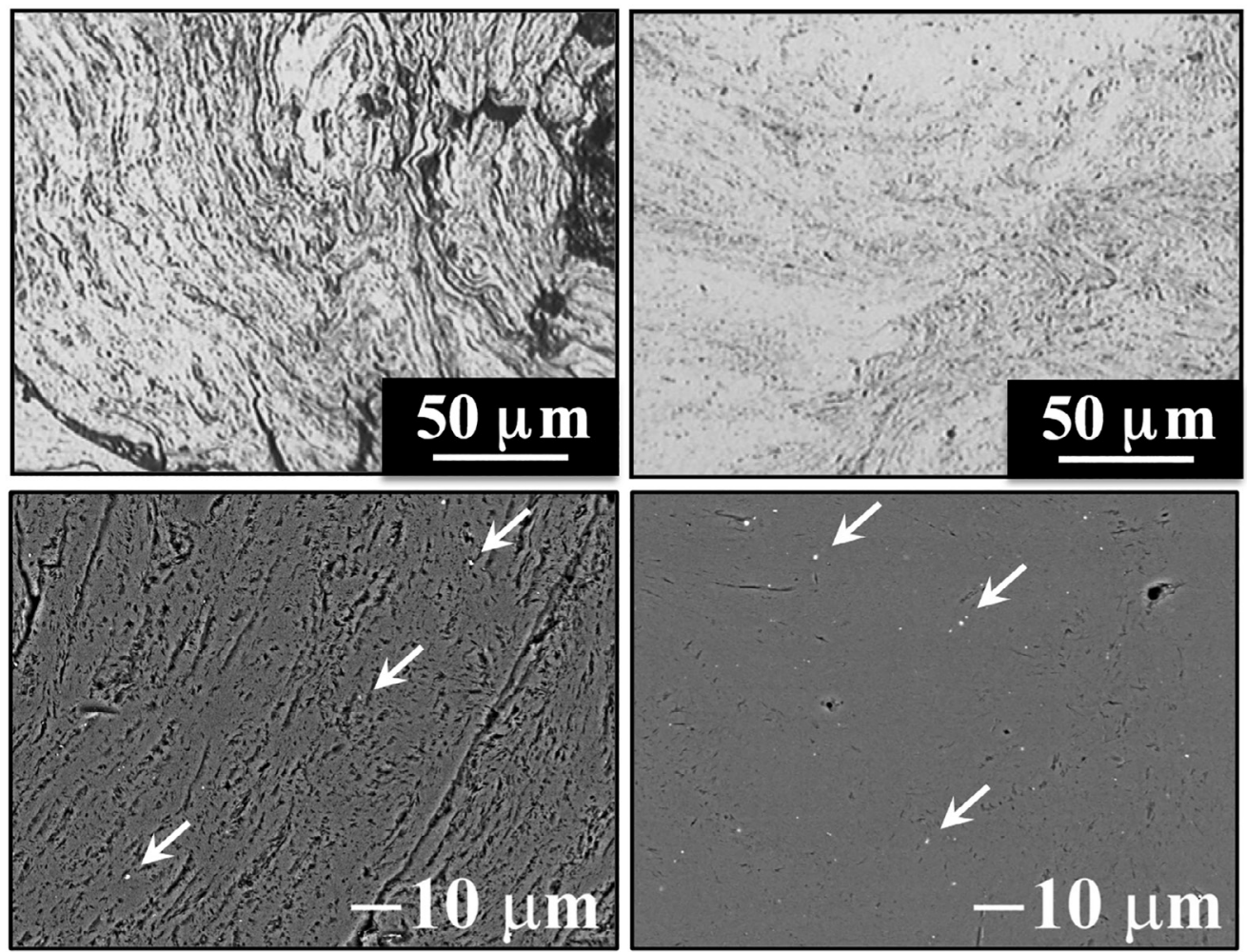
a) $1 \mathrm{~h}$
b) $8 \mathrm{~h}$
c) $1 \mathrm{~h}$
d) $8 \mathrm{~h}$

Figure 2. Cross section optical images of $\mathrm{Al}$ milled samples a) $1 \mathrm{~h}$ and b) $8 \mathrm{~h}$. SEM-BSE micrographs of Al-1.0\%MG composites milled c) $1 \mathrm{~h}$ and d) $8 \mathrm{~h}$, white bright dots are the MG particles embedded in the metal matrix. 

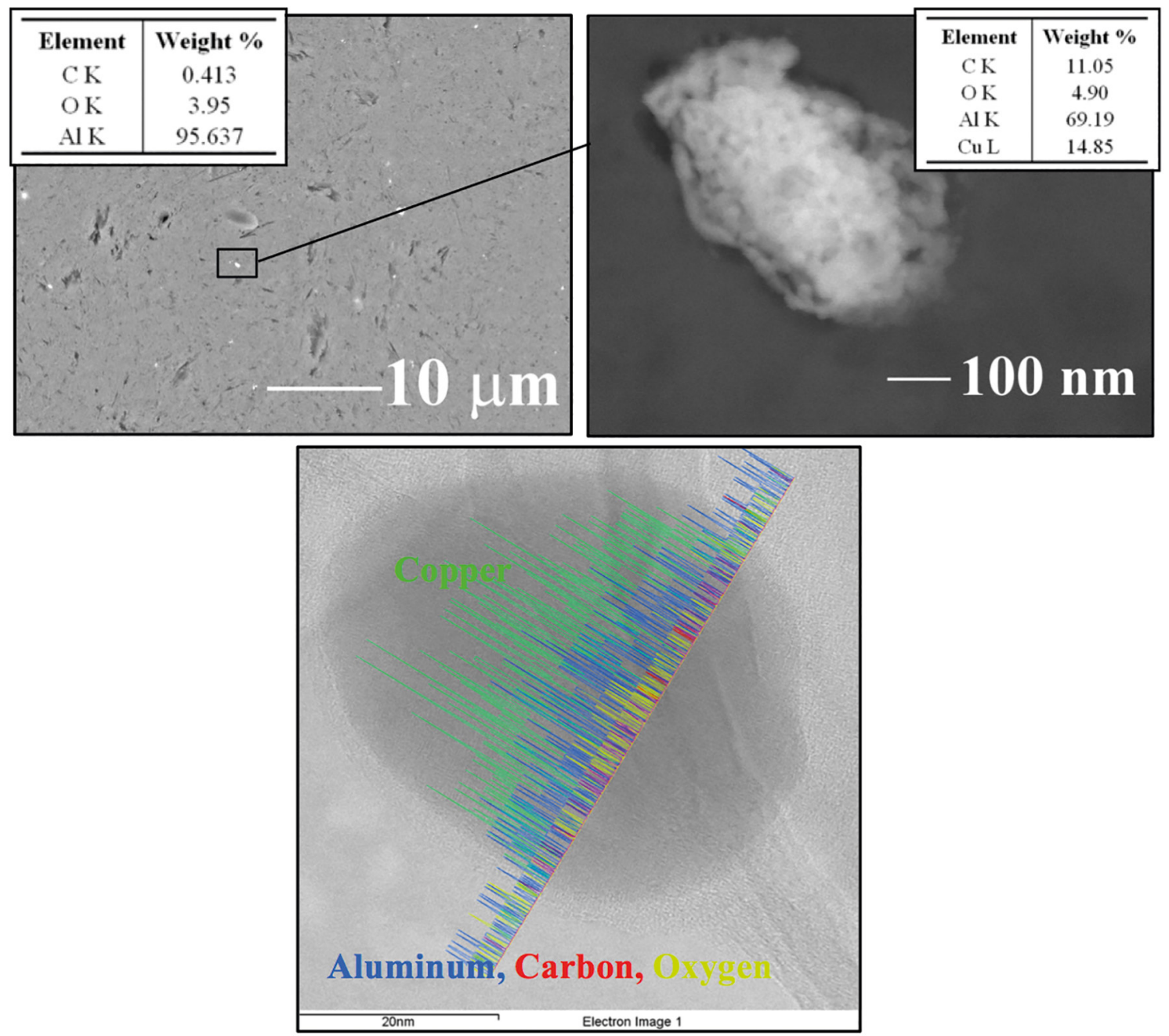

a) SEM-BSE Al-1\%MG-8h

c) TEM-BF MG particle

b) SEM-BSE MG particle

Figure 3. a) SEM-BSE micrograph of Al-1\%MG- $8 \mathrm{~h}$ composite after sintering process, the tabulated data shows the general composition of composite, b) SEM-BSE image of MG particle with its elemental composition and c) TEM-BF micrograph of a single MG particle showing the chemical distribution of components.

hardening and grain refining. The change in lattice parameter is measured by the distortion and shift of characteristics Al peaks. Variations in the $\mathrm{Al}$ (111) reflection are observed in Figure 4 along with the grain size determination as a function of milling time and MG addition. The absence of shift suggests a limited presence of dissolved $\mathrm{Cu}$ into the Al matrix by milling. In the SEM micrographs (Figures $3 \mathrm{a}$ and $3 b$ ) the MG particles remain distributed within the Al matrix and they do not dissolve. In Figure $4 \mathrm{~b}$ are given the results of grain size based on the reflection (111) for Al. This calculations were conducted using the WilliamsonHall method ${ }^{26}$. It is observed a clear reduction of the grain size even for short milling times (1h). After this sharp reduction in grain size, it stays almost constant up to $8 \mathrm{~h}$ of milling; final grain sizes are about $35 \mathrm{~nm}$ for further milled samples. The presence of MG particles does not affect the grain size evolution due these possible causes: There is a critical concentration of particles of second phase that allow a grain size reduction, in our study 0.5 and $1.0 \%$ (in weight) apparently is not enough to induce further grain refining. If we reach a minimum critical size, any addition of particles or further milling, induce an opposite behavior (grain growth).

\subsection{Density}

This parameter is measured as a general approach to assess the soundness of the mechanical performance of specimens. Figure 5 shows the effect of milling time on density of the composite samples. It is of interest that denser products are associated with lower milling 


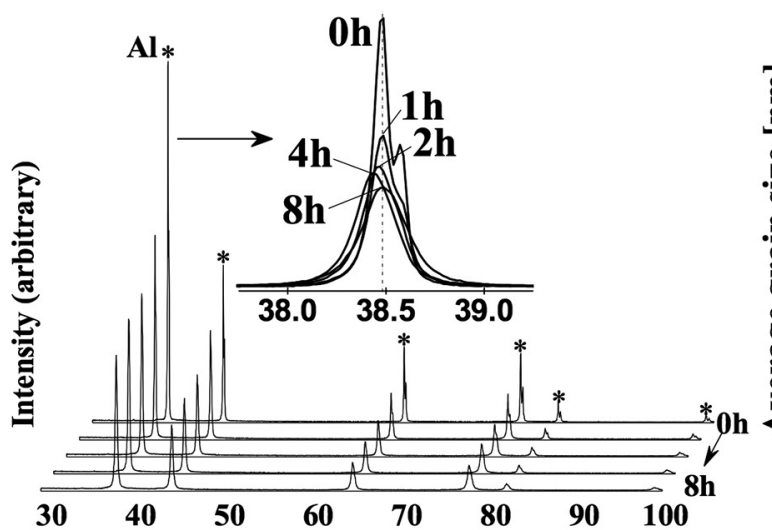

Two Theta (degrees)

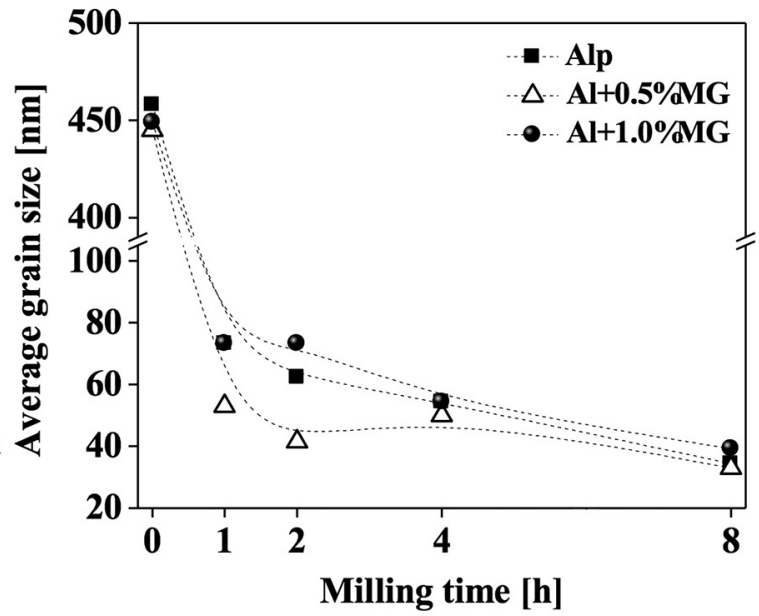

b) grain measures

a) $\mathrm{XRD} \mathrm{Al}+0.5 \% \mathrm{MG}$

Figure 4. a) XRD patterns of $\mathrm{Al}+0.5 \% \mathrm{MG}$ composite after milling time with a close up on aluminum (111) main diffraction peak and b) composites grain measures calculated from $\mathrm{Al}$ (111) plane.

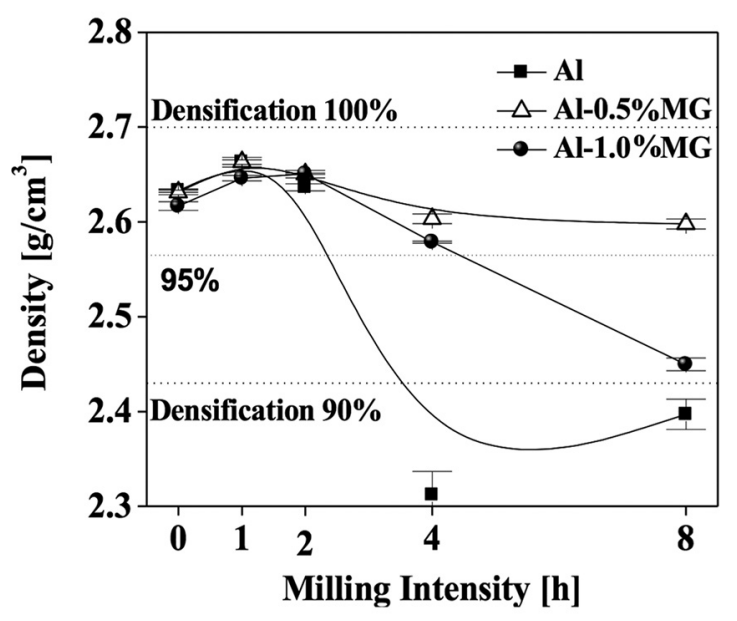

Figure 5. Density variation of sintered samples as a function of the milling time and MG addition.

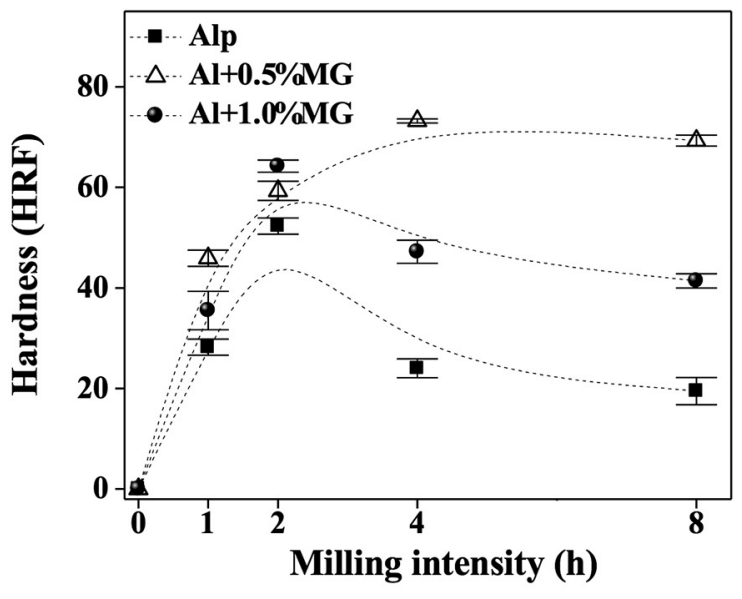

a) Hardness times $(<2 \mathrm{~h})$. These samples have a broad particle size distribution, which allows them to become denser due to a high interstitial occupancy by the smaller particles in the vacant spaces. Contrary, samples with $4 \mathrm{~h}$ of milling present an important decrease in density caused essentially by poor packing of particles due their increased hardness by severe deformation ${ }^{27}$, this behavior has been previously reported ${ }^{28}$. In addition, the presence of MG particles also affects the densification, because the modification of particle size distribution due increased small particles generation. The densification in the studied samples reach values above $95 \%$ with respect to the theoretical. The exceptions are samples Al-4h, Al-8h and Al-0.50\%MG-8h. Although a stable state was reached with the composites after $8 \mathrm{~h}$ of milling, this does not necessarily mean that densification level increases too. On the contrary, it is evident that the

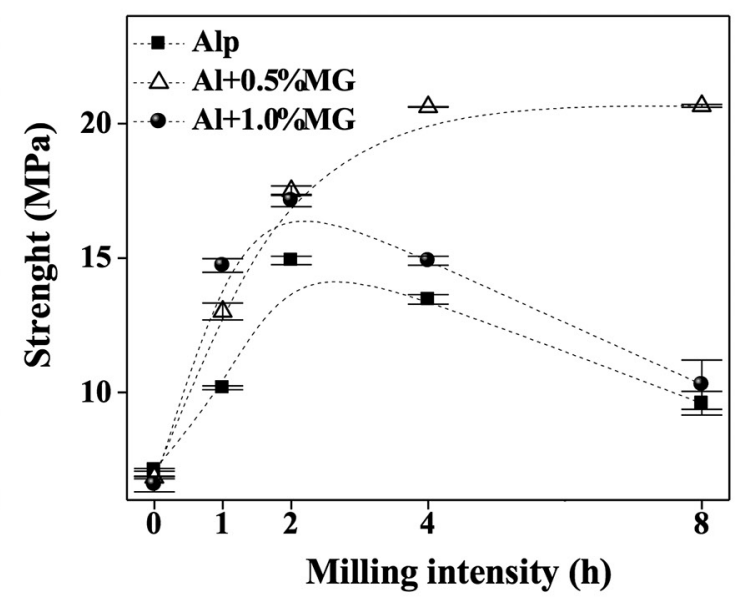

b) Strength

Figure 6. Mechanical response of composites: a) Hardness and b) strength as a function of milling time. 
density is negatively affected when the powder particles are severely deformed by further milling resulting an increase of work hardening. Because, the particles with high levels of plastic deformation do not compact efficiently (due their reduced ductility), the samples reach low-density values due high porosity derived from poor compaction of powder particles as mentioned above.

\subsection{Mechanical Testing}

Sintered samples prepared from mixed powders (Al0h, Al-0.5\%MG-0h and Al-1.0\%MG-0h) present lower hardness when are compared with their milled counterparts. In Figures $6 \mathrm{a}$ and $6 \mathrm{~b}$ can be observed that both: milling time and MG additions have a direct influence on the mechanical properties of composites. For instance the hardness increased exponentially from $0 \mathrm{HRF}$ in the raw samples to $28(\mathrm{Al}), 46(\mathrm{Al}-0.5 \% \mathrm{MG})$ and 36 (Al-1.0\%MG) after just $1 \mathrm{~h}$ of milling, as the first part of the plot shows (Figure $6 \mathrm{a}$ ). With $2 \mathrm{~h}$ of milling, we reach the optimum processing time, where the mechanical properties are maximized for Al (52) and Al-1.0\%MG (64) composite. Meanwhile the composite prepared with the composition Al-0.5\%MG with $4 \mathrm{~h}$ of milling reaches a value of $73 \mathrm{HRB}$ (the highest hardness value of studied samples). The Figure $6 \mathrm{~b}$ presents a graph of the strength of the composites as a function of milling time. In the figure can be noticed that the mechanical performance of the prepared composites is related with hardness and strength, show a similar behavior (dotted lines): values ranging from a minimum at $0 \mathrm{~h}$ (unmilled samples), passing for an optimum ( 2 or $4 \mathrm{~h}$ ) showing a fall of the properties with $8 \mathrm{~h}$ of milling. This pattern can be attributed to grain size reduction, increase of porosity, poor bonding between particles, etc. For this study, the highest strength in Al sample is $15 \mathrm{MPa}$ and $17 \mathrm{MPa}$ in the Al-1.0\%MG composite, in both cases the best mechanical properties were observed in the samples milled for $2 \mathrm{~h}$. On the other hand, the composite Al-0.05\%MG presented the highest strength of all $(20.6 \mathrm{MPa})$ with $4 \mathrm{~h}$ of milling. This represents a $37 \%$ and a $24 \%$ improvement in strength with respect to pure aluminum and the $\mathrm{Al}-1.0 \% \mathrm{MG}$ composite.

\section{Conclusions}

The Al-MG composites produced herein demonstrated that milling improves homogeneity, grain size reduction and strength. The X-ray results show that there is no solid solution between $\mathrm{Al}$ and the added reinforcements, which is observed by the lack of shifting of the Al (111) reflection. The SEM studies show the microstructure changes as a function of the milling time and MG particles concentration. The TEM results demonstrated that the reinforcement particles (MG) are core-shell structures where the core is copper and the shell carbon, which prevents the dissolution of copper by $\mathrm{Al}$; however, this does not prevent the integration of the MG particles in the matrix having clear improvements in mechanical characteristics. The composite with the best mechanical properties is $\mathrm{Al}-0.50 \% \mathrm{MG}$ milled for $4 \mathrm{~h}$ having a hardness of $73 \mathrm{HRF}$ and an elastic limit of 20.6 MPa. Further possessing and higher $\mathrm{MG}$ concentration cause a reduction of $43 \%$ on hardness and $50 \%$ on strength with respect to the Al-0.5\%MG. For Al (52 HRF/14.9 MPa) and Al-1wt\%MG the $(64 \mathrm{HRF} / 17.1 \mathrm{MPa})$ best mechanical properties were found in the samples milled for $2 \mathrm{~h}$.

\section{Acknowledgments}

This research was supported by CONACYT (Project No. 169262). Thanks to D. Lardizábal-Gutierrez, W. Antúnez-Flores and E. Torres-Moye for their valuable technical assistance.

\section{References}

1. Achutha MV, Sridhara BK, Abdul Budan D. A reliability based stress-life evaluation of aluminium-graphite particulate composites. Materials \& Design. 2008;29(4):769-774.

2. Xu Z, Ma L, Yan J, Yang S, Du S. Wetting and oxidation during ultrasonic soldering of an alumina reinforced aluminum-coppermagnesium $(2024 \mathrm{Al})$ matrix composite. Composites Part A: Applied Science and Manufacturing. 2012;43(3):407-414.

3. Suresha S, Sridhara BK. Effect of silicon carbide particulates on wear resistance of graphitic aluminium matrix composites. Materials \& Design. 2010;31(9):4470-4477.

4. Suresha S, Sridhara BK. Wear characteristics of hybrid aluminium matrix composites reinforced with graphite and silicon carbide particulates. Composites Science and Technology. 2010;70(11):1652-1659.

5. Y1lmaz O, Buytoz S. Abrasive wear of $\mathrm{Al}_{2} \mathrm{O}_{3}$-reinforced aluminium-based MMCs. Composites Science and Technology. 2001;61(16):2381-2392.

6. Yilmaz SO. Comparison on abrasive wear of $\mathrm{SiCrFe}, \mathrm{CrFeC}$ and $\mathrm{Al}_{2} \mathrm{O}_{3}$ reinforced $\mathrm{Al} 2024$ MMCs. Tribology International. 2007;40(3):441-452.

7. Lipecka J, Andrzejczuk M, Lewandowska M, Janczak-Rusch J, Kurzydłowski KJ. Evaluation of thermal stability of ultrafine grained aluminium matrix composites reinforced with carbon nanotubes. Composites Science and Technology. 2011;71(16):1881-1885.

8. Hashim J, Looney L, Hashmi MSJ. Metal matrix composites: production by the stir casting method. Journal of Materials Processing Technology. 1999;92-93:1-7.

9. Gudlur P, Boczek A, Radovic M, Muliana A. On characterizing the mechanical properties of aluminum-alumina composites. Materials Science and Engineering: A. 2014;590;352-359.

10. Besterci M. Preparation, microstructure and properties of Al$\mathrm{Al}_{4} \mathrm{C}_{3}$ system produced by mechanical alloying. Materials \& Design. 2006;27(5):416-421. 
11. Akhlaghi F, Pelaseyyed SA. Characterization of aluminum/ graphite particulate composites synthesized using a novel method termed "in-situ powder metallurgy". Materials Science and Engineering: A. 2004;385(1-2):258-266.

12. Akhlaghi F, Zare-Bidaki A. Influence of graphite content on the dry sliding and oil impregnated sliding wear behavior of Al 2024-graphite composites produced by in situ powder metallurgy method. Wear. 2009;266(1-2):37-45.

13. Liao J, Tan MJ. Mixing of carbon nanotubes (CNTs) and aluminum powder for powder metallurgy use. Powder Technology. 2011;208(1):42-48

14. Lahiri D, Hadjikhani A, Zhang C, Xing T, Li LH, Chen Y, et al. Boron nitride nanotubes reinforced aluminum composites prepared by spark plasma sintering: Microstructure, mechanical properties and deformation behavior. Material Science and Engineering: A. 2013;574:149-156.

15. Esawi AMK, Morsi K, Sayed A, Taher M, Lanka S. Effect of carbon nanotube (CNT) content on the mechanical properties of CNT-reinforced aluminium composites. Composites Science and Technology. 2010;70(16):2237-2241.

16. Shamanian M, Mohammadnezhad M, Szpunar J. Texture analysis of a friction stir welded ultrafine grained $\mathrm{Al}-\mathrm{Al}_{2} \mathrm{O}_{3}$ composite produced by accumulative roll-bonding. Journal of Alloys and Compounds. 2014;615:651-656.

17. Silvestre N, Faria B, Lopes JNC. Compressive behavior of CNTreinforced aluminum composites using molecular dynamics. Composites Science and Technology. 2014;90:16-24.

18. Suryanarayana C. Mechanical alloying and milling. Progress in Materials Science. 2001;46(1-2):1-184.

19. Hassan MTZ, Esawi AMK, Metwalli S. Effect of carbon nanotube damage on the mechanical properties of aluminium-carbon nanotube composites. Journal of Alloys and Compounds. 2014;607:215-222.
$2^{0}$. Kim WJ, Lee SH. High-temperature deformation behavior of carbon nanotube (CNT)-reinforced aluminum composites and prediction of their high-temperature strength. Composites Part A: Applied Science and Manufacturing. 2014;67:308-315.

21. Robles Hernández FC, Calderon HA. Nanostructured $\mathrm{Al} / \mathrm{Al}_{4} \mathrm{C}_{3}$ composites reinforced with graphite or fullerene and manufactured by mechanical milling and spark plasma sintering. Materials Chemistry and Physics. 2012;132(2-3):815-822.

22. Ted Guo ML, Tsao CYA. Tribological behavior of aluminum/ $\mathrm{SiC} /$ nickel-coated graphite hybrid composites. Materials Science and Engineering: A. 2002;333(1-2):134-145.

23. Yang JB, Lin CB, Wang TC, Chu HY. The tribological characteristics of $\mathrm{A} 356.2 \mathrm{Al}$ alloy $/ \mathrm{Gr}\left({ }_{\mathrm{p}}\right)$ composites. Wear. 2004;257(9-10):941-952.

24. Estrada-Guel I, Carreño-Gallardo C, Cardoso-Cortés JL, RochaRangel E, Herrera-Ramírez JM, Martínez-Sánchez R. Effect of metallic addition on mechanical properties in an aluminumgraphite composite synthesized by means of mechanical milling. Journal of Alloys and Compounds. 2010;495(2):403-407.

25. ASM International. ASM Handbook Volume 3: Alloy Phase Diagrams. 10th ed. Materials Park: ASM Internation; 1992.

26. Williamson GK, Hall WH. X-ray line broadening from filed aluminium and wolfram. Acta Metallurgica. 1953;1(1):22-31.

27. Razavi Hesabi Z, Simchi A, Seyed Reihani SM. Structural evolution during mechanical milling of nanometric and micrometric $\mathrm{Al}_{2} \mathrm{O}_{3}$ reinforced $\mathrm{Al}$ matrix composites. Materials Science and Engineering: A. 2006;428(1-2):159-168.

28. Fogagnolo JB, Robert MH, Ruiz-Navas EM, Torralba JM. 6061 Al reinforced with zirconium diboride particles processed by conventional powder metallurgy and mechanical alloying. Journal of Materials Science. 2004;39(1):127-132. 